\title{
Serial ulnar nerve conduction velocity measurements in normal subjects ${ }^{1,2}$
}

\author{
MICHAEL P. MCQUILLEN AND FRED J. GORIN ${ }^{3}$
}

From the Department of Neurology, University of Kentucky Medical Center, Lexington, Kentucky, U.S.A.

The introduction 20 years ago of techniques for measuring nerve conduction velocity in man in vivo (Hodes, Larrabee, and German, 1948) was an important milestone in the evaluation of patients with neuromuscular disorders. Careful studies of the effect of altering stimulus and recording parameters, and of the variations induced by age and physical factors, delimited the normal ranges of velocity measurements (Carpendale, 1956; Hendriksen, 1956; Thomas and Lambert, 1960; Mavor and Libman, 1962; Gamstorp and Shelbourne, 1965). However, little is known about the normal variation of nerve conduction velocity measurements in a single subject.

For this reason, serial measurements were made in the forearm segment of the left ulnar nerve in each of five healthy adult males. Velocity was expressed in three separate fashions. The mean values for two of the three measures were distinct statistically for the group as a whole, and in four of the five subjects. The variance of each measure in each subject was narrow. Thus, serial measurements are felt to be a reliable means of monitoring nerve function in different fibre populations over time.

\section{METHODS}

Percutaneous stimuli were delivered to the left ulnar nerve at the elbow and wrist through a bipolar, salinemoistened pad, stimulating electrode (DISA $13 \mathrm{~K} \mathrm{62).}$ Just maximal stimuli were employed throughout. The cathode was the distal electrode of the bipolar pair. The muscle action potential evoked by this stimulation was picked up by a solder disc bipolar surface recording electrode (DISA 13 K 60) placed over the belly and tendon of the abductor digiti quinti muscle. This potential was suitably amplified (DISA 14 A 20) and displayed on a storage oscilloscope (Tectronix RM 564) for measurement and subsequent photography. When stimulating at

'Presented together with serial data on patients with idiopathic polyneuritis, at the 20th Annual Meeting of the American Academy of Neurology, Chicago, 26 April 1968.

${ }^{2}$ Supported in part by Research Grant T-447 from the American Cancer Society.

${ }^{3} \mathrm{Mr}$. Gorin's work as a summer student fellow was supported by Training Grant VRA 311-T from the Vocational Rehabilitation Administration. the wrist, the surface stimulating electrode at the elbow was converted to a surface recording electrode, through $\frac{\overline{ }}{\bar{N}}$ an input transformer (Rushworth, Thorne, and Young, 1966). In this setting a nerve action potential, evoked $\mathbb{\complement}$ antidromically in motor fibres and orthodromically in sensory fibres-for example, in mixed nerve-was $\infty$ recorded in like manner.

The distance between the centre of the stimulating cathodes, as measured on the skin, was taken to be the $\vec{\omega}$ nerve conduction distance. Distal distance was measured from the centre of the stimulating cathode at the wrist to the centre of the recording electrode over the belly of the abductor digiti quinti muscle.

Conduction velocity in metres per second $(\mathrm{m} / \mathrm{sec}) \mathrm{N}_{\mathrm{N}}$ was derived by dividing conduction distance in metres $\vec{A}$ conduction time in seconds. In the case of motor nerve conduction velocity, conduction time was the differenge between proximal latency (from stimulus at the elbow response in the hand) and distal latency (from stimulus $>$ at the wrist to response in the hand). For mixed nereg conduction velocity, conduction time was measurat directly from stimulus at the wrist to the initial negatis peak of the nerve action potential recorded at the elbow Using a bipolar recording technique, it was felt theoretically that this point coincided in time with passage of the wave of depolarization past the first or nearest surface electrode (Buchthal and Rosenfalck, 1966). Invariably, the nerve action potential was recorded as a simple $\frac{\AA}{\mathbb{D}}$ diphasic wave.

All measurements were obtained in the same lab- $\overrightarrow{\vec{p}}$ oratory. The laboratory is air conditioned, and is maintained at an ambient temperature of 23 to $24^{\circ} \mathrm{C}$. The study group was composed of five healthy adult males, ranging in age from 22 to 33 . Neurological examination was entirely normal in all subjects. Each of the subjects was studied in the afternoon twice weekly for a total of nine trials each, during June through:September 1966. Three of the subjects served as observers. 3 . They made measurements on each other, and on the other two subjects in a random fashion. This approach $\frac{3}{3}$ was taken to simulate the normal functioning of an active electromyography laboratory, in which serial measure- $\frac{\text { 이 }}{2}$ ments on the same patient may be obtained at different $>$ times by different observers.

\section{RESULTS}

Since the data were obtained by three different ${ }_{\mathcal{W}}^{N}$ observers, it was necessary to exclude skew intro-0 
duced by any of them. Consequently, measurements of motor nerve conduction time were used as a test for observer 'precision' and bias. Two pairs of time measurements were obtained at each trial, one after stimulation at the elbow and the other after stimulation at the wrist. One measurement of each pair (direct method) was made directly on the oscilloscope screen, from stimulus artefact to onset (and peak) of muscle action potential response. Stimulus artefact was set to occur at the beginning of the trace. Sweep speed was one or two milliseconds per centimetre $(\mathrm{msec} / \mathrm{cm})$. The second measurement of each pair (indirect method) was made using a delayed sweep generator (Tectronix 3B3). In this recording mode, a continuously variable calibrated sweep delay, linear to within $0.2 \%$ of full scale from $5 \mu \mathrm{sec}$ to $2 \mathrm{sec}$ of delay, was employed. The onset of the sweep was delayed by a precision potentiometer, accurate to $1 \%$ of full scale. Following delay, the trace was displayed at a sweep speed of $100 \mu \mathrm{sec} / \mathrm{cm}$. Latency to onset was calculated from the potentiometer set to the point where the trace departed from the baseline. Latency to peak was calculated from the potentiometer at the point where the trace achieved a maximal value. Information obtained by observers from non-observer subjects only was compared. Sufficient data were available for only two observers. The difference between direct and indirect methods at each trial were recorded. The mean difference and its standard deviation (SD) were calculated for onset and peak measurements for each observer (Fig. 1). By this method of comparison, their observations were equally 'precise'-for example, they had the same SD-and overlapped sufficiently for no evidence of bias to be detected.

Conduction velocities were expressed in three fashions: as velocity in mixed nerve $(\mathrm{Vm})$, as onset motor velocity (Vo), and as peak motor velocity $(\mathrm{Vp})$. Since $\mathrm{Vm}$ is derived from stimulation of both motor and sensory nerve fibres, it is a measure of nerve function that is different anatomically from Vo and Vp. Vo and Vp should reflect the function of different components of the motor nerve fibre populations. Thus, Vo, obtained by employing latencies to the onset of the grouped muscle action potential response, should mirror function in the fastest motor fibres which arrive to produce the earliest muscle fibre depolarizations. In like manner, $\mathrm{Vp}$, obtained by employing latencies to the initial negative peak of the grouped response-that is, the point at which more muscle fibres are beginning to repolarize than are continuing to depolarizeshould be an expression of the most common (modal) motor nerve fibre velocity.

From the Table, it can be seen that the mean

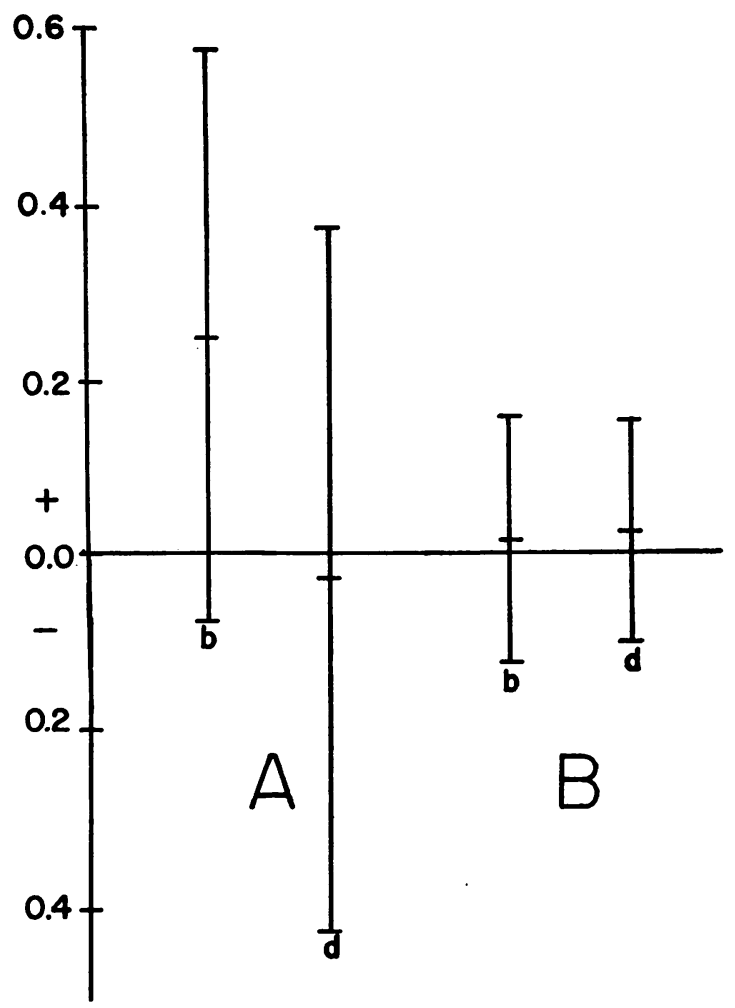

FIG. 1. Precision and bias of observers $b$ and $d$. Mean $(+2 S D)$ difference between direct and indirect method of recording distal latency to onset $(A)$ and peak $(B)$ of muscle action potential. Ordinate, difference in msec. See text for details.

values obtained for $\mathrm{Vo}, \mathrm{Vm}$, and $\mathrm{Vp}$ are differentalthough the range of each of the measurements overlaps, $\mathrm{Vo}$ is faster than $\mathrm{Vm}$ and $\mathrm{Vp}$. This is true in the group as a whole, and in all subjects. When subjected to statistical analysis, ${ }^{1}$ the hypothesis that Vo differed from $\mathrm{Vm}$ was true to a very significant degree $(P>0.01)$ in all subjects. Vo differed from $\mathrm{Vp}$ in two subjects (c and e) to a very significant degree, and to a significant degree $(P>0.05)$ in another subject (b). For the group as a whole, Vo differed from both $\mathrm{Vp}$ and $\mathrm{Vm}$ to a highly significant degree $(P>0 \cdot 001)$. No significant difference between $\mathrm{Vm}$ and $\mathrm{Vp}$ was detected.

An attempt was made to correlate distal latency and distance, for measurements on motor nerve. ${ }^{2}$ As Simpson (1956) had predicted, no significant correlation was found for the group as a whole

${ }^{1}$ A two-tailed $t$ test was used. Analyses were performed on an IBM 7040 computer at the University of Kentucky Computing Center. 'Intercorrelation matrix analyses were produced on an IBM $7040 \mathrm{com}$ puter at the University of Kentucky Computing Center. 
TABLE

DATA FROM NORMAL SUBJECTS

\begin{tabular}{|c|c|c|c|c|c|c|c|c|c|c|c|c|c|}
\hline Subject & Age & Mean & $\begin{array}{c}\text { Motor } \\
S D^{1}\end{array}$ & ${ }_{\text {Range }}^{\text {nset }}$ & Mean & $\begin{array}{l}\text {-Velocity } \\
\text { Mixed } \\
\text { SD }\end{array}$ & Range & \multicolumn{3}{|c|}{ Mean ${ }^{\text {Motor peak }}$ Range } & \multicolumn{3}{|c|}{ Mean \begin{tabular}{ccc}
\multicolumn{2}{c}{ Distal Latency } \\
SD
\end{tabular}} \\
\hline $\begin{array}{l}\text { a } \\
\text { b } \\
\text { c } \\
\text { d } \\
\text { e }\end{array}$ & $\begin{array}{l}33 \\
25 \\
24 \\
33 \\
22\end{array}$ & $\begin{array}{l}55 \cdot 4 \\
56 \cdot 6 \\
61 \cdot 7 \\
57 \cdot 9 \\
56 \cdot 0\end{array}$ & $\begin{array}{l}2.9 \\
1.1 \\
2.9 \\
1.5 \\
1.6\end{array}$ & $\begin{array}{l}49 \cdot 5-58 \cdot 3 \\
54 \cdot 6-58 \cdot 2 \\
58 \cdot 4-63,6 \\
55 \cdot 0-60 \cdot 2 \\
53 \cdot 6-58 \cdot 0\end{array}$ & $\begin{array}{l}52 \cdot 2 \\
54 \cdot 6 \\
58 \cdot 5 \\
56 \cdot 2 \\
53 \cdot 7\end{array}$ & $\begin{array}{l}1 \cdot 8 \\
1.5 \\
1.8 \\
0.9 \\
1.5\end{array}$ & $\begin{array}{l}48 \cdot 7-54 \cdot 2 \\
52 \cdot 0-56 \cdot 4 \\
57 \cdot 8-61 \cdot 4 \\
53 \cdot 0-56 \cdot 9 \\
51 \cdot 5-56 \cdot 2\end{array}$ & $\begin{array}{l}55 \cdot 3 \\
54 \cdot 6 \\
57 \cdot 4 \\
57 \cdot 1 \\
49 \cdot 9\end{array}$ & $\begin{array}{l}3 \cdot 7 \\
2 \cdot 2 \\
3 \cdot 3 \\
0 \cdot 8 \\
4 \cdot 6\end{array}$ & $\begin{array}{l}48 \cdot 0-49 \cdot 0 \\
51 \cdot 9-57 \cdot 8 \\
52 \cdot 3-64 \cdot 3 \\
55 \cdot 8-58 \cdot 1 \\
38 \cdot 1-52 \cdot 6\end{array}$ & $\begin{array}{l}3 \cdot 1 \\
2 \cdot 3 \\
2 \cdot 4 \\
2 \cdot 4 \\
2 \cdot 6\end{array}$ & $\begin{array}{l}0 \cdot 3 \\
0 \cdot 2 \\
0 \cdot 3 \\
0 \cdot 2 \\
0 \cdot 1\end{array}$ & $\begin{array}{l}2 \cdot 6-3 \cdot 4 \\
2 \cdot 0-2 \cdot 6 \\
2 \cdot 0-3 \cdot 0 \\
2 \cdot 1-2 \cdot 7 \\
2 \cdot 5-2 \cdot 8\end{array}$ \\
\hline Group & 27 & $57 \cdot 5$ & $3 \cdot 1$ & $49 \cdot 5-63 \cdot 6$ & $55 \cdot 0$ & $2 \cdot 6$ & $48 \cdot 7-61 \cdot 4$ & $54 \cdot 4$ & $4 \cdot 1$ & $38 \cdot 1-64 \cdot 3$ & $2 \cdot 6$ & 0.4 & $2 \cdot 0-3 \cdot 4$ \\
\hline
\end{tabular}

${ }^{1} \mathrm{SD}=$ standard deviation.

(Fig. 2). This was true whether latency to onset or peak of the muscle action potential response was used in the correlation matrix. When each individual's measurements were looked at separately, a good fit was observed in only one subject (d). The correlation was better for peak latency (coefficient $=0.925$ ) than it was for onset latency (coefficient $=$ 0.768 ). Nevertheless, the range of distal onset latencies was narrow (Table), and similar to that observed by Carpendale (1956).

\section{DISCUSSION}

The measurement of nerve conduction velocity is an important tool in the evaluation of patients with neuromuscular disorders (Mavor and Libman, 1962). By using it, the function of motor, large sensory, and motor plus large sensory (that is, mixed) nerve fibres can be studied. Normal function within each fibre population is documented when the population conducts evoked impulses within a normal velocity range. Different methods of stimulation and recording allow selective study of different fibre populations. Dawson (1956), Mayer (1963), and Kemble and Peiris (1967) compared velocities obtained in the same segment of nerve by the different methods in adult subjects without neurological disease. They found a significant difference between the velocities in motor, sensory, and mixed nerve fibres. Usually, velocity was fastest in sensory fibres and slowest in motor fibres. Buchthal and Rosenfalck (1966), on the other hand, were able to confirm a significant difference between motor and sensory fibres in the ulnar nerve only when comparing conduction time along the entire arm. After introducing the greater variable of conduction distance, the resultant velocities varied at random.

In the present study of ulnar nerve function in the forearm, motor conduction velocity was expressed in two different ways: as the velocity obtained by employing latencies to the onset of the muscle action क potential response (Vo), and as that obtained from $\overrightarrow{0}$ latencies to the initial negative peak of the response $\vec{\overrightarrow{ }}$ (Vp). It was hypothesized that Vo mirrored function $\vec{\omega}$ in fastest motor fibres, and Vo, the modal motor nerve velocity. This hypothesis was derived from the anatomical observation that the motor end plates $\omega$ in the abductor digiti quinti muscle lie in a narrow $N$ plane in the centre of the gross muscle (Desmede्? 1958). Since the range of conduction velocity in $\vec{A}$ muscle fibres is quite narrow, the time course of the muscle action potential recorded by surface eleco trodes reflects the sequential arrival of nerve impulses $\frac{D}{2}$ in the end plate region. Thus, impulses in the fastea nerve fibres will reach the muscle first, and give rise. $\overrightarrow{0}$ to the onset of the grouped muscle action potentia 8 By the time the initial negative peak of the potential is reached, the modal arrival of nerve impulses has peaked, and more muscle fibres are beginning to repolarize than are continuing to depolarize. $\mathrm{Vm}$, representing the response to stimulation of motor and sensory fibres in mixed nerve, is anatomically distinct from both Vo and Vp.

In the forearm segment of the ulnar nerve, Vo was faster than $\mathrm{Vp}$ - to a highly significant degree in the group as a whole, to a very significant degree in two subjects, and to a significant degree in another. Thus, the hypothetical difference between $V o$ and $V p$ is born out statistically. The anatomical difference between $\mathrm{Vm}$ and the motor velocities was more difficult to demonstrate. Vo was faster than $\mathrm{Vm}$ to a very significant degree in the group as a whole and in all subjects, individually. No statistical difference between $V m$ and $V p$ was observed. Since $V m$ was derived from the peak of the nerve action potential (see Methods), it represents a modal velocity, like $V p$. Only a quarter of the mixed nerve action potential is derived from sensory fibres (McQuillen and Johns, 1967). With the remaining three-quarters contributed by motor nerve, it is not surprising that 


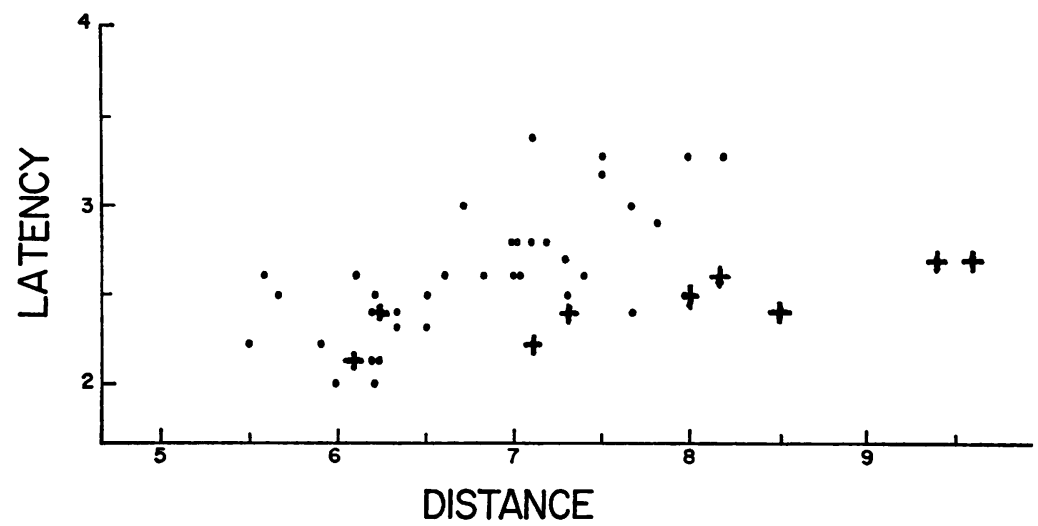

FIG. 2. Correlation between latency and distance. Significant correlation (coefficient $=0.728)$ seen only for subject $d$ (crosses). Ordinate: latency from stimulation at wrist to onset of muscle action potential, in msec. Abscissa: distance from stimulus cathode at wrist to recording cathode over hypothenar eminence, in cm.

these two measures of modal velocity, $\mathrm{Vm}$ and $\mathrm{Vp}$, are not statistically distinct in normal adult subjects.

The probability that each of these methods will express the same velocity at each measurement of a given subject appears quite good. Thus, the standard deviation (SD) for $\mathrm{Vm}$ did not exceed $1.8 \mathrm{~m} / \mathrm{sec}$ in any individual; and the limits of SD for $\mathrm{Vo}(2.9 \mathrm{~m} / \mathrm{sec})$ and $\mathrm{Vp}(4.6 \mathrm{~m} / \mathrm{sec})$ were almost as narrow (see Table). The range of normal variation varied from a minimum of $2.3 \mathrm{~m} / \mathrm{sec}$ (for $\mathrm{Vp}$ in subject d) to a maximum of $14.5 \mathrm{~m} / \mathrm{sec}$ (for $\mathrm{Vp}$ in subject $\mathrm{e}$ ). This 'reliability factor' has been estimated only rarely in the past, and usually by paired observations only. Christie and Coomes (1960) studied the normal variations in Vo for median and ulnar nerve in one subject. Measurements of ulnar Vo on four different days had a SD of $4.9 \mathrm{~m} / \mathrm{sec}$. Carpendale (1956) found that paired measurements of distal latency-that is, the time from onset of stimulus at the wrist or ankle to the onset of the evoked muscle action potential in the hand or footvaried no more than $0.4 \mathrm{msec}$ in each of 17 subjects. The SD about the mean of this measurement was no greater than $0.3 \mathrm{msec}$ in any of our five subjects (see Table).

Thus, serial studies of $\mathrm{Vo}, \mathrm{Vp}$, and $\mathrm{Vm}$ would seem to be a reliable method for monitoring the function of different nerve fibre populations in normal adults. Against the background of this data, it should be possible to interpret the changes observed in certain disease states (Simpson, 1956; Tenckhoff, Boen, Jebsen, and Spiegler, 1965; Bergamini, Gandiglio, and Fra, 1966). In this fashion, valid conclusions can be drawn as to the pathophysiology of the neuritis (Kaeser and Lambert, 1962; Simpson, 1962, 1964), and a monitor can be had as to the effects of treatment (Jebsen, Tenckhoff, and Honet, 1967).

\section{SUMMARY}

Conduction velocities were measured in the left ulnar nerve on nine separate occasions in each of five normal adult male subjects. Values obtained were expressed in three fashions: as the velocity in the fastest motor fibres; as the modal velocity among motor fibres; and as the velocity in mixed nerve. The standard deviation about the mean velocity did not exceed $4.6 \mathrm{~m} / \mathrm{sec}$ for any of the three velocities in any subject. A significant difference between two of the three measures was found in the group as a whole. Thus, serial measurements of nerve conduction velocity are a reliable means of monitoring function in different fibre populations in the forearm segment of ulnar nerve. This data provides a basis for the interpretation of similar studies in disease states.

The authors wish to acknowledge the generous assistance of John V. Haley, Ph.D., for counsel in planning and interpreting the statistical analyses, and of Arthur Meyer, A.B., for performing the analyses on the IBM 7040 computer.

\section{REFERENCES}

Bergamini, L., Gandiglio, G., and Fra, L. (1966). Motor and afferent nerve conduction in the Guillain-Barre-Strohl syndrome: a longitudinal study in five cases with different clinical features. Electromyography, 6, 205-232.

Buchthal, F., and Rosenfalck, A. (1966). Evoked action potentials and conduction velocity in human sensory nerves. Brain Res., 3, 1-122.

Carpendale, M. T. F. (1956). Conduction Time in the Terminal Portion of the Motor Fibres of the Ulnar, Median and Peroneal Nerves in Healthy Subjects and in Patients with Neuropathy. M.S. Thesis, Mayo Foundation, Graduate School of the University of Minnesota.

Christie, B. G. B., and Coomes, E. N. (1960). Normal variation of nerve conduction in three peripheral nerves. Ann. phys. Med., 5, 303-309, and 326.

Dawson, G. D. (1956). The relative excitability and the conduction velocity of sensory and motor nerve fibres in man. J. Physiol. (Lond.), 131, 436-451. 
Desmedt, J. E. (1958). Méthodes d'étude de la fonction neuromusculaire chez l'homme. Myogramme isométrique electromyogramme d'excitation et topographie de l'innervation terminale. Acta neurol. belg., 58, 977-1017.

Gamstorp, I., and Shelbourne, S. A., Jr. (1965). Peripheral sensory conduction in ulnar and median nerves of normal infants, children, and adolescents. Acta paediat. Scand., 54, 309-313.

Hendriksen, J. D. (1956). Conduction Velocity of Motor Nerves in Normal Subjects and Patients with Neuromuscular Disorders. Thesis, Mayo Foundation, Graduate School of the University of Minnesota.

Hodes, R., Larrabee, M. G., and German, W. (1948). The human electromyogram in response to nerve stimulation and the conduction velocity of motor axons. Studies on normal and on injured peripheral nerves. Arch. Neurol. Psychiat. (Chic.), 60, 340-365.

Jebsen, R. H., Tenckhoff, H., and Honet, J. C. (1967). Natural history of uremic polyneuropathy and effects of dialysis. New Engl. J. Med., 277, 327-333.

Kaeser, H. E., and Lambert, E. H. (1962). Nerve function studies in experimental polyneuritis. Electroenceph. clin. Neurophysiol., Suppl. no. 22, 29-35

Kemble, F., and Peiris, O. A. (1967). General observations on sensory conduction in the normal adult median nerve. Electromyography, 7, 127-140.
Mavor, H., and Libman, I. (1962). Motor nerve conduction velocity measurement as a diagnostic tool. Neurology (Minneap.), 12, 733-744.

Mayer, R. F. (1963). Nerve conduction studies in man. Neurology (Mineapp.), 13, 1021-1030.

McQuillen, M. P., and Johns, R. J. (1967). The nature of the defect in the Eaton-Lambert syndrome. Neurology (Mineapp.), 17, 527-536.

Rushworth, G., Thorne, J., and Young, R. R. (1966). A simple and inexpensive method of increasing the signal-to-noise ratio for $\Omega$ recording human nerve action potentials. J. Physiol. (Lond.), 184, 67P-69P.

Simpson, J. A. (1956). Electrical signs in the diagnosis of carpal tunnel and related syndromes. J. Neurol. Neurosurg. Psychiat., 19, 275-280.

- (1962). Conduction velocity of peripheral nerves in human $\stackrel{\vec{T}}{\longrightarrow}$ metabolic disorders. Electroenceph. clin. Neurophysiol.,으 Suppl. no. 22, 36-43. (1964). Biology and disease of the peripheral nerves. Brit. med., $\frac{\bar{\sigma}}{\frac{\sigma}{T}}$.
J., 2, 709-714.

Tenckhoff, H. A., Boen, F. S. T., Jebsen, R. H., and Spiegler, J. H. (1965). Polyneuropathy in chronic renal insufficiency. J. Amer. med. Ass., 192, 1121-1124.

Thomas, J. E., and Lambert, E. H. (1960). Ulnar nerve conduction velocity and H-reflex in infants and children. J. appl. Physiol., $\vec{\odot}$ 15, 1-9. 